\title{
Correction to: Urinary podocyte-derived microparticles in youth with type 1 and type 2 diabetes
}

\author{
Katie M. Sullivan ${ }^{1,2} \cdot$ James Scholey $^{3,4}$ (1) Rahim Moineddin ${ }^{5}$ (I) Etienne Sochett ${ }^{2} \cdot$ Brandy Wicklow $^{6,7}$. \\ Yesmino Elia ${ }^{2}$. Fengxia Xiao ${ }^{8}$. Thalia Medeiros ${ }^{8}$ - Pusha Sadi ${ }^{6,7} \cdot$ Dylan Burger $^{8}$ (D) Farid H. Mahmud ${ }^{2}$ (D) \\ Alison B. Dart ${ }^{6,7}$
}

Published online: 4 November 2020

(C) Springer-Verlag GmbH Germany, part of Springer Nature 2020

\section{Correction to: Diabetologia \\ https://doi.org/10.1007/s00125-020-05297-z}

The names Fengxia Xiao and Thalia Medeiros were spelt incorrectly in the author list. The details are corrected here.

Publisher's note Springer Nature remains neutral with regard to jurisdictional claims in published maps and institutional affiliations.

The online version of the original article can be found at https://doi.org/ 10.1007/s00125-020-05297-z

Katie M. Sullivan

KatieMarie.Sullivan@pennmedicine.upenn.edu

1 Renal Electrolyte and Hypertension Division, Department of Medicine, Perelman School of Medicine, University of Pennsylvania, Philadelphia, PA, USA

2 Department of Pediatrics, The Hospital for Sick Children, University of Toronto, Toronto, ON, Canada

3 Department of Medicine, University of Toronto, Toronto, ON, Canada

4 University Health Network, University of Toronto, Toronto, ON, Canada

5 Department of Family and Community Medicine, University of Toronto, Toronto, ON, Canada

6 Department of Pediatrics and Child Health, University of Manitoba, Winnipeg, MB, Canada

7 Diabetes Research Envisioned and Accomplished in Manitoba (DREAM), Children's Hospital Research Institute of Manitoba, Winnipeg, MB, Canada

8 Kidney Research Centre, Department of Medicine, Ottawa Hospital Research Institute, University of Ottawa, Ottawa, ON, Canada 